\title{
Consequence modelling of a dust explosion
}

\author{
N. A. Rahman \& M. S. Takriff \\ Department of Chemical and Process Engineering, \\ Universiti Kebangsaan Malaysia, Malaysia
}

\begin{abstract}
A dust explosion is a serious hazard in process industries where combustible dust is handled. Dust explosion commonly occurs in a confined space such as a silo, a vessel or a warehouse. Based on industrial accidents involving a dust explosion, it may cause death, injuries and property damage. Therefore, a practical approach for integrated risk management of dust explosion hazards is required. This research focuses on the development of a spreadsheet tool for predicting the severity of dust explosion. The consequence modelling is required to enable the assessment of risk associated with dust explosion. Various published models were studied for initial work of consequence modelling. Parameters considered were the dust deflagration index $\left(\mathrm{K}_{\mathrm{st}}\right)$, the maximum explosion pressure $\left(\mathrm{P}_{\max }\right)$, the maximum rate of pressure rise $(\mathrm{dP} / \mathrm{dt})_{\max }$ and the laminar burning velocity $\left(\mathrm{S}_{\mathrm{lbv}}\right)$. Reliable value for these dust explosion parameters have been tabulated based on closed vessel laboratory tests. A case study of dust explosion involving maize starch in closed vessel was used to test and validate the developed consequence modelling tool. The modelling result was discussed by comparing the predicted value against experimental value. The spreadsheet tool that was developed in this work can be used for the purpose of risk management of a facility associated with dust explosion hazards. It can be used to assist the application to combustion suppressant agent and design of explosion venting to prevent and mitigate the consequence of dust explosion.

Keywords: dust explosion, consequence modelling, risk assessment.
\end{abstract}

\section{Introduction}

Dust explosion will occur when five elements called "Explosion Pentagon" is fully occupied. The first three elements needed to cause a dust fire (fire triangle) are combustible dust (fuel), ignition source (heat or spark) and oxygen in air. 
Additional elements needed for a dust explosion is dust dispersion and confinement where pressure to be generated [1]. Dust explosion can be categorized as serious hazard; it causes death, injuries, property damage and economic losses. According to Malaysia's DOSH report [2] for the past ten years, there were two cases involving dust explosion in Malaysia. In March 2008 , there was an accident at grain storage and milling plant which caused four death and two injuries. It also caused widespread damaged to the silo tower facility, the main building and interconnected underground tunnel which housed the continuous conveyors and ancillaries from a jetty to the basement floor of the silo tower. Then in the early November 2010, there was an accident at a motorcycle rim manufactured factory which caused injuries to eight workers where two of them were serious injured. It also caused extensive damage to buildings and manufacturing plant, the destruction of the dust collector system and also broke windows of nearby factories. Because of serious consequences of dust explosion, a practical solution should be considered for integrated risk management system for dust explosion hazards and risk.

The risk assessment of dust explosion consists of two crucial components. They are the likelihood of the dust explosion occurring and the severity of the consequences. This research will only focus on the latter. Consequence modelling is the typically used to determine the severity of a given hazard once it is realized. Several models have been developed and reported in the literature for predicting the consequence of dust explosion. For example, Dahoe et al. [3] and Di Benedetto and Russo [4] used a similar model to evaluate the thermo-kinetic parameters of dust explosion based on the combustion reaction by assuming that the pyrolysis/devolatilization step is very fast and then gas combustion is controlling dust explosion.

It is advantageous to have a user friendly computerized tool in readily available software for predicting the severity of a dust explosion. Thus, this research focuses on the development of a spreadsheet tool on Microsoft Excel ${ }^{\mathbb{R}}$ for predicting various dust explosion parameters such as the maximum rate of pressure rise $\left((\mathrm{dP} / \mathrm{dt})_{\max }\right)$ the maximum explosion pressure $\left(\mathrm{P}_{\max }\right)$, the dust deflagration index $\left(\mathrm{K}_{\mathrm{st}}\right)$ and the laminar burning velocity $\left(\mathrm{S}_{\mathrm{lbv}}\right)$. These parameters are used to measure the severity of a dust explosion through the consequence modelling.

\section{Description of consequence modelling}

Important parameters for consequence modelling of dust explosion are the maximum rate of pressure rise $\left((\mathrm{dP} / \mathrm{dt})_{\max }\right)$ the maximum explosion pressure $\left(\mathrm{P}_{\max }\right)$, and the dust deflagration index $\left(\mathrm{K}_{\mathrm{st}}\right)$ and the laminar burning velocity $\left(\mathrm{S}_{\mathrm{lbv}}\right)$. The dust deflagration index, $K_{s t}$ is defined as the maximum rate of pressure rise times the cube root of the vessel volume (Eckhoff [5]) and its relation to the maximum rate of pressure rise is shown in eqn. (1)

$$
\left(\frac{\mathrm{dP}}{\mathrm{dt}}\right)_{\max } \mathrm{V}^{1 / 3}=\mathrm{K}_{\mathrm{st}}
$$


This equation can be used to determine the performance of the dust explosion. The robustness of the explosion increases with the maximum rate of pressure increase, the deflagration index $\mathrm{K}_{\mathrm{St}}$ increase (Crowl and Louvar [6]). Based on the value of the deflagration index, dusts are classified into four classes. These St Classes are shown in Table 1.

Table 1: $\quad$ Dust explosion classes.

\begin{tabular}{ccc}
\hline Deflagration index,$K_{s t}($ bar $\mathrm{m} / \mathrm{s})$ & St class & Characteristic \\
\hline 0 & $\mathrm{St}-0$ & no explosion \\
$1-200$ & $\mathrm{St}-1$ & weak explosion \\
$200-300$ & $\mathrm{St}-2$ & strong explosion \\
$>300$ & $\mathrm{St}-3$ & very strong explosion \\
\hline
\end{tabular}

The consequences of a dust explosion in a confined space such as a vessel or a building can be predicted through cubic root law relationship;

$$
\left[\left(\frac{d P}{d t}\right)_{\max } V^{1 / 3}\right]_{\text {in vessel }}=\left[\left(\frac{d P}{d t}\right)_{\max } V^{1 / 3}\right]_{\text {experiment }}
$$

In practice, eqn. (2) is used to design the actual plant-sized equipment by applying standard test results from laboratory-sized vessels (Dahoe et al. [3]). The predicted values from eqn. (2) will be more accurate if the experiments were carried out as close as possible to the actual conditions under consideration (Crowl and Louvar [6]). For example the cubic root law is applicable for varying size of vessels with similar geometrical of vessels if the flame thickness is negligible compared to vessel radius, similar burning velocity in all volumes and point ignition at the centre of vessels (Dahoe et al. [3]).

Table 2: $\quad$ Model of laminar dust flame in a spherical closed vessel.

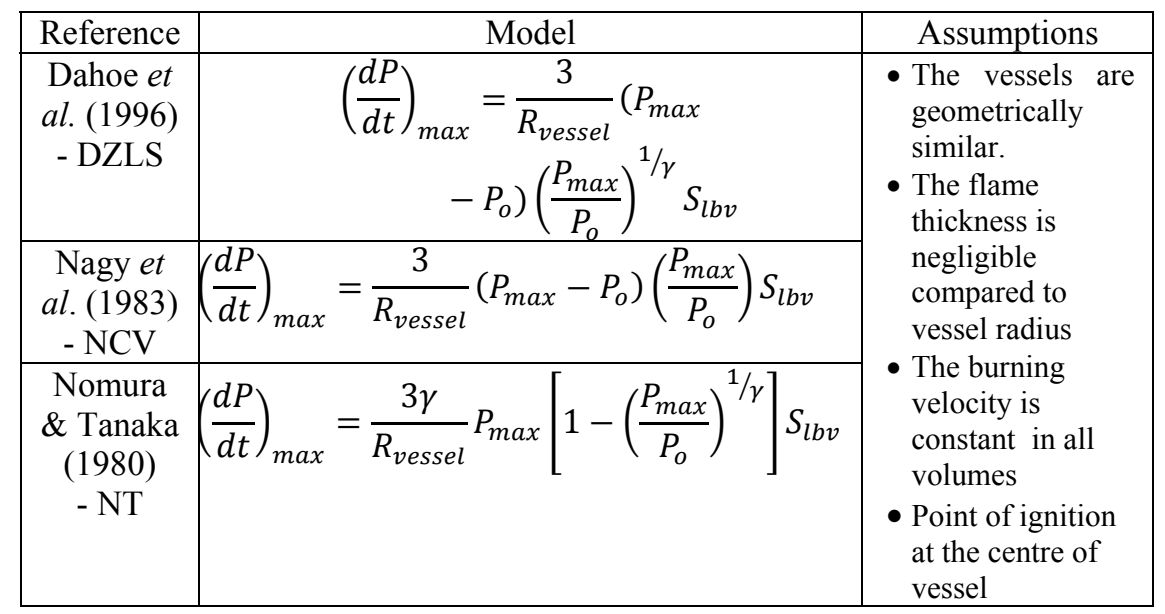


The laminar burning is the linear rate of combustion reaction zone propagates relative to the unburned gas of flammable mixture. It was adopted from premixed gas property theory and therefore the specifications of laminar dust explosion and laminar gas explosion in closed vessel should be similar Eckhoff [5]. Several models were developed based on theories of laminar flame propagation during the closed vessel explosion such as Dahoe et al. [3], Nagy et al. (Eckhoff [5]) and Nomura and Tanaka (Eckhoff [5]). These models are shown in table 2 .

In this study, these three models are compared within the limitation of the cubic law for selecting the best model of dust explosion's consequence modelling. The dust explosion parameters considered were the laminar burning velocity $\left(S_{l b v}\right)$, the maximum explosion pressure $\left(P_{\text {max }}\right)$, the maximum rate of pressure rise $\left((\mathrm{dP} / \mathrm{dt})_{\max }\right)$ and the dust deflagration index $\left(K_{S t}\right)$. Reliable value for these dust explosion parameters have been tabulated and compared with experimental data for spherical closed vessel laboratory test in the $20 \mathrm{~L}$ or $1 \mathrm{~m}^{3}$ spherical vessel that have been reported in the literature. It is noted that $(\mathrm{dP} / \mathrm{dt})_{\max }$ was obtained when the pressure attains its maximum pressure $(P=$ $\left.P_{\text {max }}\right)$, the initial pressure of the dust cloud $\left(P_{0}=1\right.$ bar $)$, and heat capacity ratio for dry air $(\gamma=1.4)$. For example, the model by Dahoe et al. [3] states that;

$$
\begin{gathered}
\left(\frac{d P}{d t}\right)=\frac{3\left(P_{\max }-P_{0}\right)}{R_{\text {vessel }}}\left[1-\left(\frac{P_{0}}{P}\right)^{1 / \gamma}\left(\frac{P_{\max }-P}{P_{\max }-P_{0}}\right)\right]^{2 / 3}\left(\frac{P}{P_{0}}\right)^{1 / \gamma} S_{l b v} \\
\left(\frac{d P}{d t}\right)_{\max }=\frac{3\left(P_{\max }-P_{0}\right)}{R_{\text {vessel }}}\left(\frac{P_{\max }}{P_{0}}\right)^{1 / \gamma} S_{l b v} \\
K_{s t}=\left(\frac{d P}{d t}\right)_{\text {max }} V^{1 / 3}=\frac{3}{R_{\text {vessel }}} V^{1 / 3}\left(P_{\max }-P_{0}\right)\left(\frac{P_{\max }}{P_{0}}\right)^{1 / \gamma} S_{l b v}
\end{gathered}
$$

If the vessel radius, $R_{\text {vessel }}$ is referred to $1 \mathrm{~m}^{3}$ spherical vessel, then $\left(\mathrm{V}=1 \mathrm{~m}^{3}, \mathrm{R}_{\text {vessel }}=(3 / 4 \pi)^{1 / 3}\right)$

$$
K_{s t}=\left(\frac{d P}{d t}\right)_{\text {max }}=\frac{3}{R_{\text {vessel }}}\left(P_{\text {max }}-P_{0}\right)\left(\frac{P_{\max }}{P_{0}}\right)^{1 / \gamma} S_{l b v}
$$

\section{Case study}

Dahoe et al. [3] performed their thin-flame model for three spherical vessels of $20 \mathrm{~L}, 1 \mathrm{~m}^{3}$ and $10 \mathrm{~m}^{3}$ volumes to predict the pressure evolution and the rate of pressure rise. Nagy et al. (Eckhoff [5]) performed their experiments in the closed Hartman bomb ranging from $1.2 \mathrm{~L}$ to $14 \mathrm{~m}^{3}$ of vessel volumes. They normalized their result using the relationship of cube root law to produce $\mathrm{K}_{\mathrm{St}}$. Table 3 shows the determination of $\mathrm{K}_{\mathrm{st}}$ value for maize starch dust cloud in air for different volumes of vessels [5,9]. From the experiment in the closed 1.2L Hartman Bomb at dust concentration of $500 \mathrm{~g} / \mathrm{m}^{3}$, at atmospheric pressure and $300 \mathrm{~K}$, the estimated burning velocity for maize starch is $0.59 \mathrm{~m} / \mathrm{s}$ with $\mathrm{P}_{\max }=7.95$ $\operatorname{bar}(\mathrm{g})$ and $(\mathrm{dP} / \mathrm{dt})_{\max }=620$ bar. Table 4 summarizes the laminar burning velocity for a maize starch in various methods [8]. Di Benedetto and Russo [4] performed 
dust explosion experiments on cornstarch as classified in St2 class and compared their simulation result with the experimental values reported in the NFPA 68 guidelines, in the database GESTISDUST-EX and in related published literatures. The maize starch dust was selected as a case study of dust explosion in a closed vessel. The maize starch data in the standard $1 \mathrm{~m}^{3} \mathrm{ISO}$ vessel at dust concentration of $60 \mathrm{~g} / \mathrm{m}^{3}, \mathrm{P}_{\max }=9.7 \mathrm{bar}(\mathrm{g})$, and $\mathrm{K}_{\mathrm{St}}=158 \mathrm{bar} . \mathrm{m} / \mathrm{s}$ in $\mathrm{St} 1$ class (Eckhoff [5]) and GESTISDUST-EX were used as reference.

Table 3: KSt values measured for clouds of maize starch dust in closed vessels based on various volumes of vessel.

\begin{tabular}{cccc}
\hline Researcher & $\begin{array}{c}(\mathrm{dP} / \mathrm{dt})_{\max } \\
(\mathrm{bar} / \mathrm{s})\end{array}$ & $\begin{array}{c}\text { Vessel Volume, V } \\
\left(\mathrm{m}^{3}\right)\end{array}$ & $\begin{array}{c}\mathrm{K}_{\mathrm{St}} \\
(\mathrm{bar} . \mathrm{m} / \mathrm{s})\end{array}$ \\
\hline Bartknecht (1978) & 680 & 0.0012 & 73 \\
Nagy \& Verakis (1983) & 612 & 0.0012 & 66 \\
Eckhoff et al. (1987) & 220 & 0.0012 & 23 \\
Nagy \& Verakis (1983) & 413 & 0.009 & 86 \\
Aldis et al. (1983) & 320 & 0.02 & 87 \\
Eckhoff et al. (1987) & 365 & 0.02 & 100 \\
Yi Kang Pu (1988) & 10 & 0.026 & 3 \\
Yi Kang Pu (1988) & 20 & 0.026 & 6 \\
Yi Kang Pu (1988) & 60 & 0.026 & 20 \\
Yi Kang Pu (1988) & 80 & 0.026 & 25 \\
Nagy \& Verakis (1983) & 272 & 0.028 & 34 \\
Bond et al. (1986) & 50 & 0.33 & 71 \\
Kauffman et al. (1984) & 72 & 0.95 & 20 \\
Kauffman et al. (1984) & 20 & 0.95 & 200 \\
Nagy \& Verakis (1983) & 136 & 3.12 & 209 \\
Nagy \& Verakis (1983) & 110 & 6.7 & 131 \\
Nagy \& Verakis (1983) & 55 & 13.4 & \\
\hline
\end{tabular}

Table 4: $\quad$ Laminar burning velocities of maize starch.

\begin{tabular}{|c|c|c|c|}
\hline Researcher & Method & $\begin{array}{c}\text { Concentration } \\
\left(\mathrm{g} / \mathrm{m}^{3}\right)\end{array}$ & $\begin{array}{c}\mathrm{S}_{\mathrm{CL}} \\
(\mathrm{m} / \mathrm{s})\end{array}$ \\
\hline Proust (1993) & Square duct $200 \times 200 \mathrm{~mm}^{2}$ & 235 & 0.27 \\
\hline Van Der Wel (1993) & Burner & $400-800$ & 0.2 \\
\hline Van Der Wel (1993) & 20-1 sphere & 400 & 0.13 \\
\hline Mazurkiewicz \& & Burner & - & 0.13 \\
\hline Jarosinski (1991) & Square duct $50 \times 50 \mathrm{~mm}^{2}$ & $260-760$ & 0.14 \\
\hline Mazurkiewicz \& & Cylindrical tube $\mathrm{d}=128 \mathrm{~mm}$ & $75-200$ & 0.59 \\
\hline Jarosinski (1994) & Cylindrical tube $\mathrm{d}=60 \mathrm{~mm}$ & $370-1200$ & 0.22 \\
\hline Pedersen \& Van & Cylindrical tube $\mathrm{d}=100 \mathrm{~mm}$ & $80-430$ & 0.4 \\
\hline Wingerden (1995) & Tube+burner (flat flame) & 330 & 0.29 \\
\hline \multicolumn{4}{|l|}{ Krause et al. (1996) } \\
\hline \multicolumn{4}{|l|}{ Krause et al. (1996) } \\
\hline Dahoe et al. (2002) & & & \\
\hline
\end{tabular}




\section{Result}

Models discuss in the preceding sections were coded into an Excel ${ }^{\circledR}$ worksheet for predicting the identified dust explosion parameters. The spreadsheet tool is very user friendly and can be used to predict the consequence of dust explosions for any confine volume and type dusts provided the required input data are available. The results of the consequence modelling for the case study is discussed in the subsequently.

Consequence modelling calculations were performed on maize starch with three burning velocities $\left(\mathrm{S}_{\mathrm{lbv}}=0.27 \mathrm{~m} / \mathrm{s}, 0.59 \mathrm{~m} / \mathrm{s}\right.$ and $\left.0.6 \mathrm{~m} / \mathrm{s}\right)$ and vessel volumes ranging from $1.2 \mathrm{~L}$ to $14 \mathrm{~m}^{3}$ by DZLS's model (Dahoe et al.), NCV's model (Nagy et al.) and NT's model (Nomura and Tanaka) for comparison within the limitation of cubic root law. Figures 1 and 2 present calculated values of the maximum rate of pressure rise $(\mathrm{dP} / \mathrm{dt})_{\max }$ as a function of the vessel radius, $R_{\text {vessel }}$ vs. experimental data. Both figures show that the maximum pressure rate, $(\mathrm{dP} / \mathrm{dt})_{\max }$ was affected by changes in volume of vessel for the three burning velocities. The $(\mathrm{dP} / \mathrm{dt})_{\max }$ are inversely proportional with values of $R_{\text {vessel }}$. The smaller volume of vessel produces a higher maximum pressure rate $(\mathrm{dP} / \mathrm{dt})_{\max }$. However, $(\mathrm{dP} / \mathrm{dt})_{\max }$ increased with increasing the values of $\mathrm{P}_{\max }$ and $\mathrm{S}_{\mathrm{lbv}}$. The value of $(\mathrm{dP} / \mathrm{dt})_{\max }$ for DZLS's model was found to be more accurate rather than NCV's model and NT's model if we compared to experimental data.

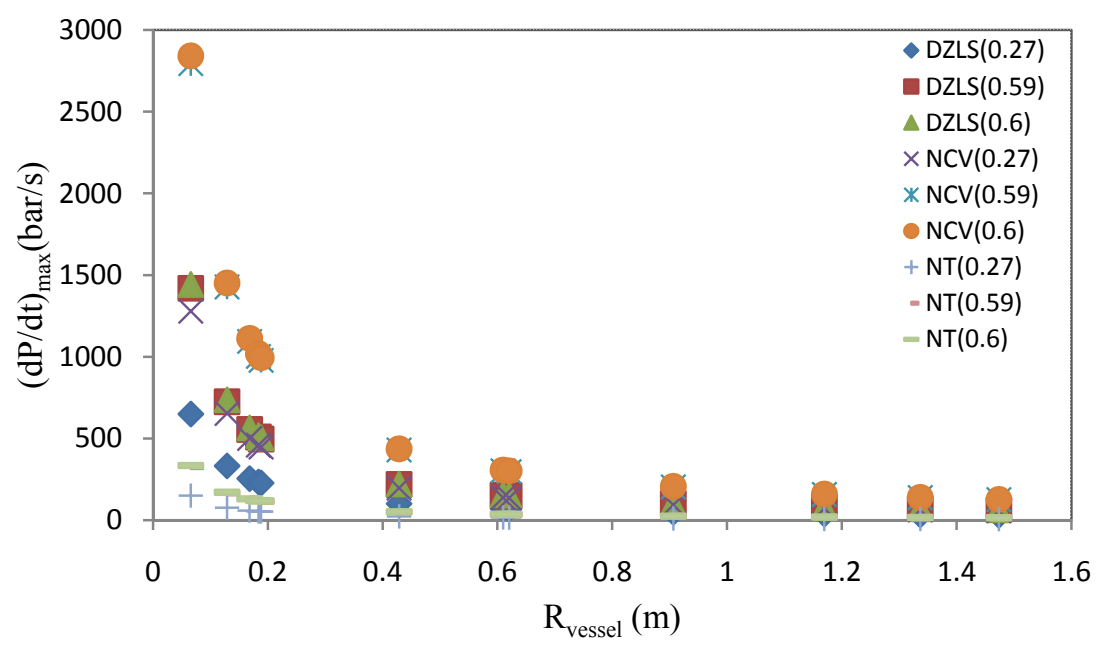

Figure 1: The maximum pressure rate, $(\mathrm{dP} / \mathrm{dt})_{\max }$ as a function of vessel radius, $R_{\text {vessel }}$ for maize starch. $\left(P_{0}=1\right.$ bar, $P_{\max }=10.713$ bar, $\gamma=1.4$, $\left.\mathrm{S}_{\mathrm{lbv}}=0.27 \mathrm{~ms}^{-1}, 0.59 \mathrm{~ms}^{-1}, 0.6 \mathrm{~ms}^{-1}\right)$. 


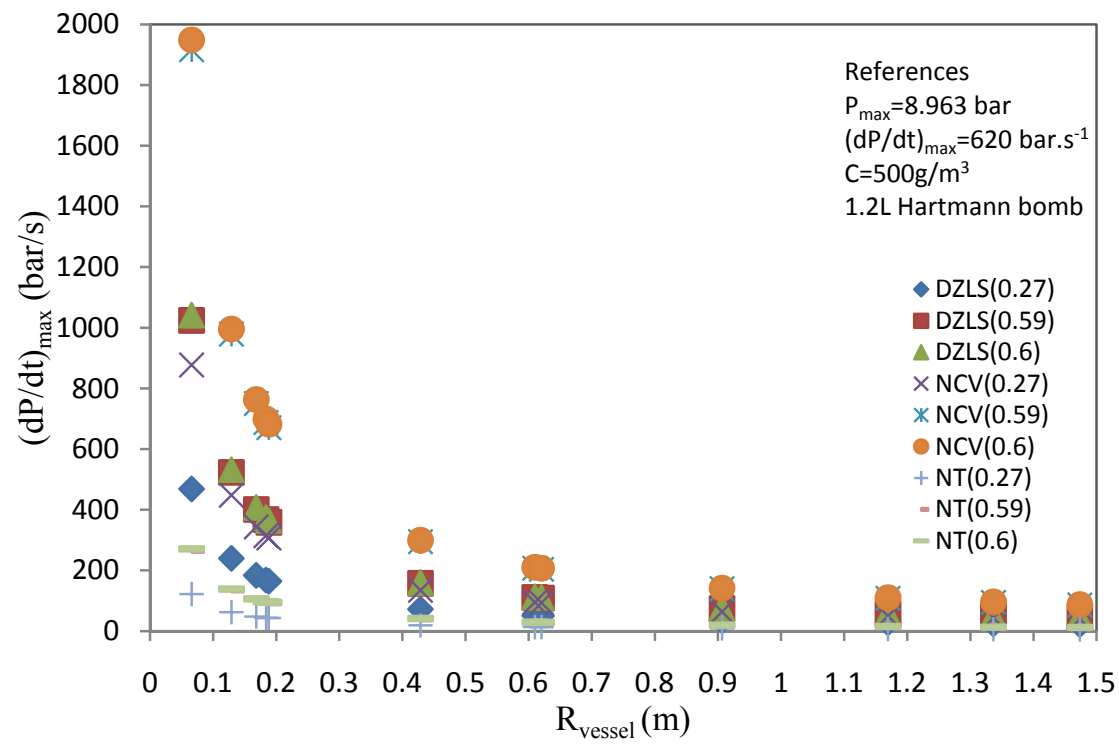

Figure 2: The maximum pressure rate, $(\mathrm{dP} / \mathrm{dt})_{\max }$ as a function of vessel radius, $R_{\text {vessel }}$ for maize starch. $\left(P_{0}=1\right.$ bar, $P_{\max }=8.963$ bar, $\gamma=1.4$, $\left.\mathrm{S}_{\mathrm{lbv}}=0.27 \mathrm{~ms}^{-1}, 0.59 \mathrm{~ms}^{-1}, 0.6 \mathrm{~ms}^{-1}\right)$.

Figure 3 and Figure 4 present calculated values of dust deflagration index, $\mathrm{K}_{\mathrm{St}}$ as a function of the vessel volume, $V_{\text {vessel }}$ vs. experimental data. Both figures show that the $\mathrm{K}_{\mathrm{St}}$ remain constant for varying volume of vessel for each model.

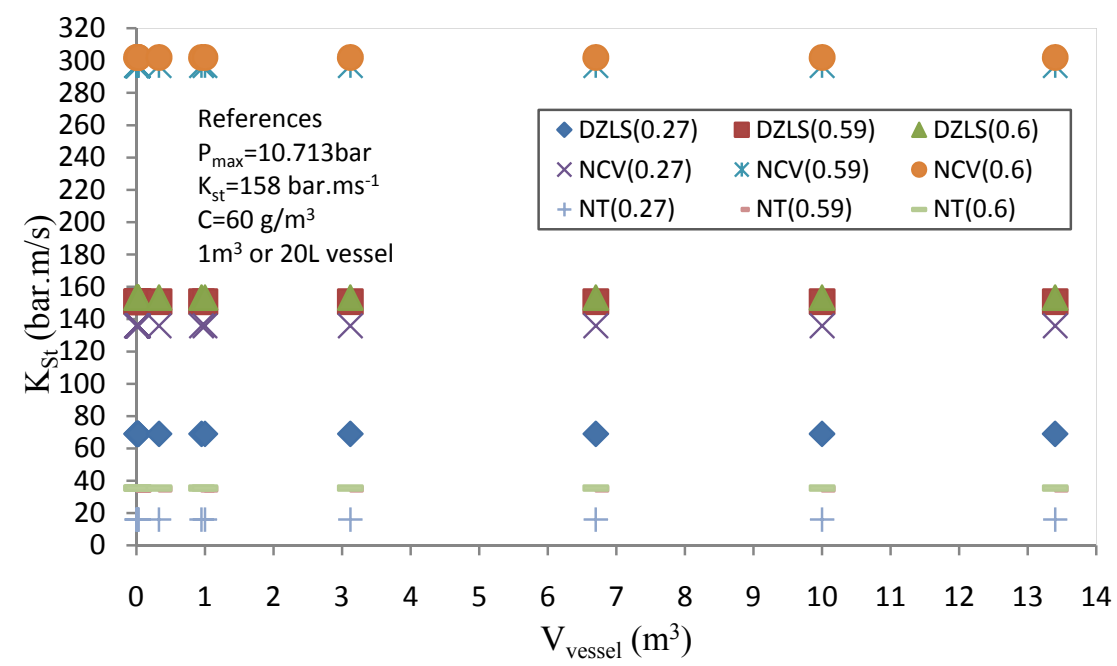

Figure 3: Model values of that the dust deflagration index, $\mathrm{K}_{\mathrm{St}}$ as a function of vessel volume, $\mathrm{V}_{\text {vessel }}$ for maize starch. $\left(\mathrm{P}_{0}=1 \mathrm{bar}\right.$, $\left.\mathrm{P}_{\max }=10.713 \mathrm{bar}, \gamma=1.4, \mathrm{~S}_{\mathrm{lbv}}=0.27 \mathrm{~ms}^{-1}, 0.59 \mathrm{~ms}^{-1}, 0.6 \mathrm{~ms}^{-1}\right)$. 
But this result does not agree with experimental result performed by Nagy et al. (1971) and Eckhoff [5] where all the three smallest vessels of 1.2L, 9L and 28L volumes gave almost similar $\mathrm{K}_{\mathrm{St}}$ values, whereas for the larger vessels of $3 \mathrm{~m}^{3}$, $6.5 \mathrm{~m}^{3}$ and $14 \mathrm{~m}^{3}$ volumes were all about twice as large. However, in this result, the $\mathrm{K}_{\mathrm{st}}$ was affected by changes in $\mathrm{P}_{\max }$ and $\mathrm{S}_{\mathrm{lbv}}$. The $\mathrm{K}_{\mathrm{st}}$ are increased with increasing the values of $\mathrm{P}_{\max }$ and $\mathrm{S}_{\mathrm{lbv}}$. As a $\mathrm{K}_{\mathrm{St}}$ result, NZLS's model with $\mathrm{P}_{\max }=10.713 \mathrm{bar}$ gave the closest value $\left(\mathrm{K}_{\mathrm{St}}=153 \mathrm{bar} . \mathrm{m} / \mathrm{s}\right)$ to experimental value $\left(\mathrm{K}_{\mathrm{St}}=158 \mathrm{bar} . \mathrm{m} / \mathrm{s}\right)$ compared to NCV's model and NT's model. So, it shows that NZLS's model more relevant than the others.

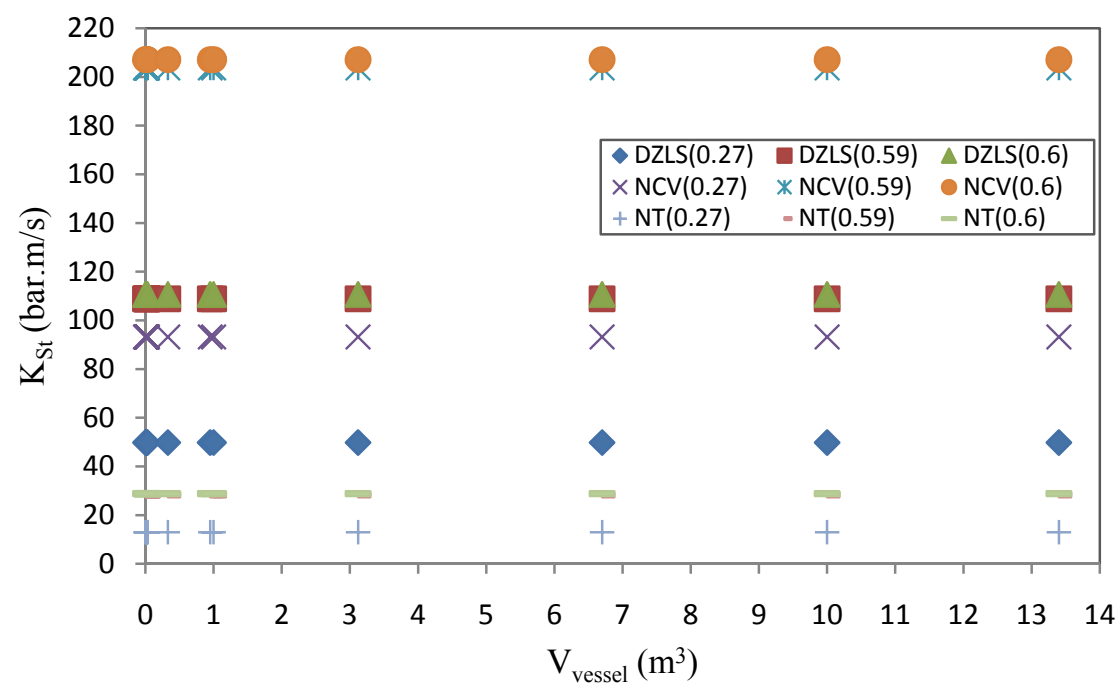

Figure 4: Model values of that the dust deflagration index, $\mathrm{K}_{\mathrm{St}}$ as a function of vessel volume, $\mathrm{V}_{\text {vessel }}$ for maize starch. $\left(\mathrm{P}_{0}=1\right.$ bar, $\mathrm{P}_{\max }=8.963$ bar, $\gamma=1.4, \mathrm{~S}_{\mathrm{lbv}}=0.27 \mathrm{~ms}^{-1}, 0.59 \mathrm{~ms}^{-1}, 0.6 \mathrm{~ms}^{-1}$ ).

\section{Discussion and conclusion}

An Excel ${ }^{\circledR}$ spreadsheet for predicting the consequence of dust explosion was successfully developed in this work based on published models and validated with published experimental data. It is a user friendly tools that requires standard input data before the consequence of a dust explosion of a dust in a given volume of confinement can be calculated. The online GESTISDUST-EX database would be a good reference for various parameters required by the spreadsheet tool that has been developed. It is noted that the geometry of the referred experimental work were all done in spherical vessels, thus used of the spreadsheet for other geometry may be used with some degree of caution on the accuracy of the results. In addition, other factors such as dust concentration and particle size may also affect the consequence of a dust explosion. The spreadsheet tool for dust explosion consequence modelling was validated by running a case study of 
dust explosion involving maize starch. The results of the consequence modelling were compared with experimental data for a similar geometry of confinement. The results of the spreadsheet tool closely matched the experimental data. Thus, it is concluded that the spreadsheet that was developed for predicting the consequence of dust explosion can be used with confidence.

The spreadsheet tool for predicting the consequence of dust explosion that is developed in this work can be used for the purpose of risk management of a facility associated with dust explosion hazards. It may used to predict the maximum pressure rise as a result of a dust explosion in a certain volume of confinement and thus, the impact of the explosion can be predicted. In addition the information can be used in the design of venting for relieving a vessel to avoid rupturing of the vessel in an event of dust explosion or to determine the time interval to apply a combustion suppressant agent such as $\mathrm{CO}_{2}$ to stop the combustion process.

\section{Acknowledgements}

The authors would like to thank Universiti Teknikal Malaysia Melaka (UTeM) and Universiti Kebangsaan Malaysia for the support and guidance. The authors would also like to acknowledge the Malaysia Ministry of Higher Education (MOHE) for funding this project.

\section{References}

[1] Combustible Dust in Industry: Preventing and Mitigating the Effects of Fire and Explosions www.osha.gov/dts/shib/shib073105.html

[2] Combustible Dust Explosion and Combustible Dust Explosion at Motorcycle Rim Manufactured Factory www.dosh.gov.my

[3] Dahoe, A.E., Zevenbergen, J.F., Lemkowitz, S.M. \& Scarlett, B., Dust explosions in spherical vessels: The role of flame thickness in the validity of the 'cube-root law'. Journal of Loss Prevention in the Process Industries, 9(1), pp. 33-44, 1996.

[4] Di Benedetto, A. \& Russo, P., Thermo-kinetic modelling of dust explosions. Journal of Loss Prevention in the Process Industries, 20, pp. 303-309, 2007.

[5] Eckhoff, R. K., Dust Explosions in the Process Industries, 3rd ed., Gulf Professional Publishing, USA, 2003.

[6] Crowl, D.A. \& Louvar, J.F., Chemical Process Safety - Fundamentals with Applications, 2nd ed., Prentice-Hall, 2002.

[7] GESTIS-DUST-EX http://biaonline.hvbg.de/EXPLOE.html

[8] Silvestrinia, M., Genovaa, B. \& Leon Trujillo, F.J., Correlations for flame speed and explosion overpressure of dust clouds inside industrial enclosures. Journal of Loss Prevention in the Process Industries, 21, pp. 374-392, 2008. 
206 Safety and Security Engineering IV

[9] Pu, Y.K., Fundamental Characteristics of Laminar and Turbulent Flames in Cornstarch Dust/Air Mixtures, Ph.D. thesis, Department of Mechanical Engineering, McGill University, 1988.

[10] A. Rahman, N. \& Takriff, M.S., Consequence Modelling of Dust Explosion. Regional Engineering Post Graduate Conference (EPC), Universiti Kebangsaan Malaysia, Malaysia, Jkkp-145, pp. 515-520, 2010. 